\title{
A Network Pharmacology-Based Investigation to the Pharmacodynamic Material Basis and Mechanisms of the Anti-Inflammatory and Anti-Viral Effect of Isatis indigotica
}

\author{
Jiuling Deng ${ }^{1, *}$ \\ Ying $\mathrm{Ma}^{2, *}$ \\ Yuqiong $\mathrm{He}^{1, *}$ \\ Hong Yang $\mathbb{D}^{2}$ \\ Yanhong Chen ${ }^{2}$ \\ Liang Wang' \\ Doudou Huang' \\ Shi Qiu ${ }^{1}$ ** \\ Xia $\mathrm{Tao}^{2}$ \\ Wansheng Chen' \\ 'Institute of Chinese Materia Medica, \\ Shanghai University of Traditional \\ Chinese Medicine, Shanghai, 20I203, \\ People's Republic of China; ${ }^{2}$ Department \\ of Pharmacy, Changzheng Hospital, \\ Second Military Medical University, \\ Shanghai, 200003, People's Republic of \\ China
}

*These authors contributed equally to this work

Correspondence: Wansheng Chen Institute of Chinese Materia Medica, Shanghai University of Traditional Chinese

Medicine, Shanghai, 20I203, People's

Republic of China

Tel +6402I 81886182

Email chenwansheng@shutcm.edu.cn

Xia Tao

Department of Pharmacy, Shanghai

Changzheng Hospital, Second Military

Medical University, Shanghai, 200003,

People's Republic of China

Tel +6402I 8I886182

Email taoxia2003@126.com
Purpose: Isatis indigotica (Ii) is a cruciferous herb that is widely distributed in China, and its roots and leaves have been used in two renowned antipyretic detoxicate crude drugs in Chinese Pharmacopoeia, Radix $(R)$ and Folium $(F)$ Isatidis. However, the pharmacodynamic material basis and underlying mechanisms of the herbal efficacy remained to be elucidated. Methods: Ultra-performance liquid chromatography-quadrupole-time-of-flight mass spectrometry (UPLC-Q-TOF-MS) was adopted for the chemical profiling of $R$ and F Isatidis. The active ingredients were screened out through the prediction of gastrointestinal absorption and druglikeness analysis using SwissADME. A herb-ingredient-target network was constructed through target prediction of the herbal active ingredients and anti-inflammation or anti-viral properties, followed by protein-protein interaction analysis. Then, the potential relevant signaling pathways were predicted by pathway enrichment. Finally, for verification, RAW 264.7 cell line was adopted to examine the anti-inflammatory and anti-viral activities of 6 representative ingredients in Ii.

Results: Seventy-three compounds have been identified from Ii through UPLC-Q-TOF-MS. A total of 17 potential active ingredients were screened through pharmacokinetics and druglikeness evaluation using SwissADME. It was shown that key targets might include TNF, AKT1, SRC, IL2, CASP9, and CASP3 in our herb-ingredient-target network, and isovitexin, a flavonoid, tended to participate in the inflammatory response, indoles were more likely to affect the cell proliferation processes, and lignans might have a broader affinity to key targets than the other active ingredients, such as regulating immune system (targeting IL-2) and PI3K-Akt signaling pathway. In vitro, indigo and secoisolariciresinol diglucoside markedly reduced TNF- $\alpha$ expression in Poly (I: C)-incubated cells. Isovitexin significantly inhibited TNF- $\alpha$ expression, and isatin treatment markedly reduced IL- $1 \beta$ expression in LPS-incubated cells.

Conclusion: As the pharmacodynamics material basis of $I i$, indoles, lignans, and flavonoids are believed to confer beneficial properties through various cellular aspects with multiple signaling pathways involved.

Keywords: Isatis indigotica, UPLC-Q-TOF-MS, network analysis, bioassay analysis

\section{Introduction}

Isatis indigotica Fortune is a cruciferous plant that is widely distributed in northern and central China, whose roots and leaves comprise two renowned antipyretic detoxicate crude drugs, Radix $(R)$ and Folium $(F)$ Isatidis. ${ }^{1-3}$ Accumulating 
evidence has shown that antipyretic detoxicate herbs might possess anti-inflammatory and anti-viral effects., $R$ Isatidis has been ethnomedically employed for the protection against the common cold and influenza in China for centuries. ${ }^{6,7}$ Notably, Banlangen (R Isatidis) Granules, namely Phynova Cold and Flu Relief Powder for Oral Solution, were the first Chinese patent medicine to be approved by the Medicines and Healthcare Products Regulatory Agency (MHRA) for marketing in the UK in 2019, for the relief of the symptoms of the common cold, mild upper respiratory tract infections (URTIs) and flu-like illness, such as sore throat, which exemplifies the antiinflammatory and anti-viral potential of $R$ Isatitis. Since they are from the same plant, $R$ and $F$ Isatidis, the roots and the leaves of $I i$, respectively, share similar chemical profiling. ${ }^{8}$ Interestingly, the two crude drugs, $R$ and $F$ Isatidis, comprise a widely accepted OTC medicine, Compound Banlangen Granules, in a ratio of 2:3 ( $R$ vs $F$ Isatidis). Therefore, it is of great value to investigate the pharmacodynamic material basis and the underlying molecular mechanism of the herbal efficacy of $I i$.

The anti-inflammatory activity of $I i$ has been previously investigated, and it was demonstrated that methanolic extracts of $R$ Isatidis could decrease the production of inflammatory mediators, in vivo and in vitro. ${ }^{9}$ The polysaccharides from $R$ Isatidis showed an in vitro inhibitory effect against virus-induced inflammation. ${ }^{10}$ Ruan et al reported that the aqueous extract of $R$ Isatidis exhibited protection on lipopolysaccharide (LPS)-induced sepsis in C57BL/6J mice. ${ }^{11}$ Xiao et al reported 6 bioactive compounds to possess in vitro antiinflammatory activity. ${ }^{12}$ Pretreatment with n-butanol extract from $F$ Isatidis could significantly inhibit LPS-induced proinflammatory factor expressions. ${ }^{13}$

The anti-viral effect of the herb has also been reported. Yang et al reported that the hot water extract of $R$ Isatidis exhibited an anti-viral effect in vitro. ${ }^{14}$ A comparative fingerprint analysis of $R$ Isatidis highlighted the hydrophilic components as more correlated to the anti-viral activity than the lipophilic parts. ${ }^{15}$ Moreover, a water-soluble isoquinoline derivative extracted from $R$ Isatidis exhibited superior anti-viral activity with an IC50 value as low as $15.3 \mu \mathrm{g} / \mathrm{mL} .{ }^{16}$ Wang et al found that an isoflavone compound isolated from the root of the herb showed excellent anti-viral activity with an IC50 as low as $2.06 \mu \mathrm{mol} / \mathrm{L} .{ }^{17} \mathrm{Nie}$ et al isolated glucosinolate alkaloids from the root, and verified the anti-viral activity in MadinDarby canine kidney (MDCK) cells (in vitro) and in embryonated eggs (in vivo). ${ }^{7}$ Moreover, polysaccharides from $R$ Isatidis were identified as the potential active ingredients. ${ }^{18}$
The anti-viral activity of $F$ Isatidis was also investigated, with relatively fewer reports. Deng et al highlighted the n-butanol fraction of the F Isatidis extract as the principal anti-viral effective substantial foundation. ${ }^{19}$

Previous studies on $I i$ did not investigate the components and the herbal efficacy comprehensively. As mentioned above, chemical characterization of $I i^{17,20,21}$ has been reported, as well as preclinical studies of single ingredients ${ }^{22-26}$ or aqueous extracts. ${ }^{11,14,18,19}$ However, there is still a need to elucidate the pharmacodynamic material basis of $I i$ in a more comprehensive manner. Here, we applied a network analysis-based integrated strategy to explore the pharmacodynamic material basis and potential mechanisms of the anti-viral and antiinflammatory effect of $I i$. First, the chemical compositions of the herb were characterized by ultra-performance liquid chromatography-quadrupole-time-of-flight mass spectrometry (UPLC-Q-TOF-MS). Second, first defined by Hopkins in $2007,{ }^{27}$ network pharmacology analysis was adopted to establish a network of "herb-active ingredients-targets" and to predict the possible molecular mechanisms by which the herb exerts its anti-inflammatory and anti-viral activity. Finally, 6 representative compounds were evaluated in vitro for their anti-inflammatory and anti-viral properties in RAW 264.7 cells, incubated with LPS, a potent trigger of macrophagemediated inflammation, ${ }^{28}$ and Poly (I: C), a mimic of viral dsRNA. $^{29}$

\section{Materials and Methods Chemicals and Herbal Materials}

The organic phase for UPLC-Q-TOF-MS, methanol and acetonitrile were purchased from Merck (NJ, USA). Bottled water (Wahaha, Hangzhou, China) was used as the aqueous phase of LC. Formic acid was obtained from Merck (NJ, USA). Methanol for extraction use was purchased from Merck (NJ, USA). Six pure compounds, including indirubin, indigo, isatin, secoisolariciresinol, secoisolariciresinol diglucoside, and isovitexin, obtained from Shanghai Yuanye BioTechnology Co., Ltd. (Shanghai, China), were used (purity $\geq 98 \%$ ) as reference standards.

Isatis indigotica Fort. (Cruciferae) was grown in the local lab and was authenticated by Professor Chen Wansheng. Freeze-dried roots and leaves were ground into powder (40 mesh) for the next extraction.

\section{UPLC-Q-TOF/MS Analysis}

The characterization of the roots and leaves of $I i$ was carried out with a model 1290 UPLC system coupled to a model 
6530 QTOF-MS (each from Agilent, Santa Clara, CA, USA) equipped with an orthogonal electrospray ionization source. Analytes in samples were separated with an ACQUITY BEH $\mathrm{C}_{18}(2.1 \times 100 \mathrm{~mm}, 1.7 \mu \mathrm{m})$ (Waters Technologies, Milford, MA, USA); the column temperature was $35^{\circ} \mathrm{C}$. The mobile phase consisted of $2 \mathrm{mM}$ ammonium acetate (A) and acetonitrile (B), and the flow rate was $0.3 \mathrm{~mL} \mathrm{~min}^{-1}$. Gradient elution was carried out as follows: $5-10 \% \mathrm{~B}$ over $0-2 \mathrm{~min}$; $10-52 \%$ B over $2-10 \mathrm{~min} ; 52-75 \%$ B over $10-15 \mathrm{~min}$. Reequilibration was at $5 \% \mathrm{~B}$ for $4 \mathrm{~min}$.

MS was performed in positive-ion mode. The operating parameters applied were as follows: scan frequency: 3.00 spectra $\mathrm{sec}^{-1}$, sheath gas flow, $11 \mathrm{~L} \mathrm{~min}^{-1}$, sheath gas temperature, $350^{\circ} \mathrm{C}$, nebulizer pressure, $45 \mathrm{psi}$, gas flow, $11 \mathrm{~L} \mathrm{~min}^{-1}$, Vcap, $3500 \mathrm{~V}$, Skimmer1, $65 \mathrm{~V}$, fragmentor, $140 \mathrm{~V}$, nozzle voltage, $500 \mathrm{~V}$. Each of the TOF-MS and TOF-MS/MS scans were operated over the $\mathrm{m} / \mathrm{z}$ range of $100-1200$. For UPLCQ-TOF-MS/MS detection, the sweeping collision energy was set to $30 \mathrm{~V}$.

Raw mass spectrum data was obtained in centroid mode, converted to the Analysis Base File (https://www. reifycs.com/AbfConverter/) format, and imported into the MS-DIAL version 4.24 (https://prime.psc.riken.jp/ compms $/ \mathrm{msdial} / \mathrm{main} . \mathrm{html}$ ) with the following parameters: $\mathrm{MS}^{1}$ tolerance, $0.01 \mathrm{Da} ; \mathrm{MS}^{2}$ tolerance, $0.02 \mathrm{Da}$; retention time range, 1-30 min; $\mathrm{MS}^{1}$ mass range, 100-1200; MS/ MS mass range, 0-1200; minimum peak height, 5000 amplitude; mass slice width, $0.1 \mathrm{Da}$; sigma window value, 0.5; MS/MS abundance cut off, 500 amplitude; retention time tolerance, $0.15 \mathrm{~min}$. Peak heights were normalized based on the height for the internal standard.

\section{Screening of Potential Active Ingredients} The SwissADME (swissadme.ch) ${ }^{30}$ tool was adopted to predict potential active ingredients. Gastrointestinal (GI) absorption was examined, and drug-likeness (DL) analysis was conducted. In general, those compounds with high GI absorption and more than 3 "Yes, 0 violation" in DL analysis were viewed as active ingredients and included for the next steps.

\section{Prediction of Associated Targets of Active Ingredients and the Herbal Efficacy, and Network Construction}

Targets associated with active ingredients and the herbal efficacy were identified through searching on Swiss Target Prediction (swisstargetprediction.ch) ${ }^{31}$ and TCMSP databases (tcmspw.com/tcmsp.php), and the Human Gene
Database (GeneCards, genecards.org), respectively. For the target prediction of the herbal efficacy, the following keywords were used: viral, anti-viral, antiviral, virus, anti-virus, antivirus, inflammatory, anti-inflammatory, antiinflammatory, inflammation, anti-inflammation, and antiinflammation. Overlapping was conducted using Microsoft Excel and visualized with Venny 2.1 (bioinfogp.cnb.csic.es/tools/ venny/) software. The protein-protein interaction (PPI) analysis was conducted using Search Tool for the Retrieval of Interacting Genes/Proteins (STRING) (string-db.org) database and visualized with Cytoscape 3.7.1 (www.cytoscape. org/) software. The nodes represented targets, compounds, pathways and edges indicated interactions.

\section{KEGG Pathway Enrichment}

The core genes, proposed by PPI analysis, were introduced into DAVID version 6.8 (Database for Annotation, Visualization, and Integrated Discovery, david.ncifcrf.gov/). Differences were considered to be statistically significant at $\mathrm{p}<0.05$.

\section{In vitro Verification}

The murine macrophage cell line RAW264.7 was purchased from the Cell Bank of the Chinese Academy of Sciences (Shanghai, China). Cells were grown and maintained in Dulbecco's Modified Eagle's Medium (DMEM, Meilunbio, Dalian, China), supplemented with $10 \%$ heat-inactivated fetal bovine serum (FBS, GIBCO, Australia), $100 \mathrm{U} / \mathrm{mL}$ of penicillin and $100 \mu \mathrm{g} / \mathrm{mL}$ of streptomycin (Beyotime, Beijing, China). Cells were cultured at $37^{\circ} \mathrm{C}$ and $5 \% \mathrm{CO}_{2}$.

\section{Cell Viability Test}

RAW264.7 murine macrophages were cultured in a 96well plate $\left(1 \times 10^{4}\right.$ cells/well $)$ for $24 \mathrm{~h}$. Medium with a final concentration of $0,1,5,10,20,60,100,200,300 \mu \mathrm{M}$ compounds was added, with each concentration repeated across 6 wells $(n=6)$. The negative control comprised cells treated with $0.1 \%$ of dimethyl sulphoxide (DMSO), diluted in complete DMEM, and incubated at $37^{\circ} \mathrm{C}$ for $24 \mathrm{~h}$. After treatment for $24 \mathrm{~h}, 10 \mu \mathrm{L}$ of Cell Counting Kit (CCK-8) assay solution (Beyotime, Beijing, China) was added to each well, and cells were incubated for $1 \mathrm{~h}$ at $37^{\circ} \mathrm{C}$ and $5 \% \mathrm{CO}_{2}$. The absorbance at $450 \mathrm{~nm}$ was measured using a microplate reader (SPARK 10M, Thermo, Tecan). Cell viability was calculated as absorbance/absorbance of control $\times 100 \%$. 


\section{ELISA Test}

RAW264.7 murine macrophages were cultured in a 48well plate $\left(1 \times 10^{5}\right.$ cells $/ 250 \mu \mathrm{L}$ per well $)$ for $24 \mathrm{~h}$, LPS $(150 \mathrm{ng} / \mathrm{mL})$ and 6 compounds $(20 \mu \mathrm{M})$ were simultaneously added for $24 \mathrm{~h}$; Poly (I: C) $(50 \mu \mathrm{g} / \mathrm{mL})$ and 6 compounds $(20 \mu \mathrm{M})$ were simultaneously added for 18 $\mathrm{h}$, with each group repeated across 6 wells in duplicates $(n=6)$. At the same time, the control group was set. Then, the cell culture medium was collected for tumor necrosis factor- $\alpha$ (TNF- $\alpha$ ), interleukin-6 (IL-6), interferon- $\beta$ (IFN- $\beta$ ), C-C motif chemokine 5 (CCL5), and interleukin-1 $\beta$ (IL-1 $\beta$ ) concentration measurements by Enzyme-linked immunosorbent assay (ELISA) kits, according to manufacturers' instructions. ELISA kits for TNF-a, IL-6, IFN- $\beta$, CCL5 and IL-1 $\beta$ were purchased from Lianke Biotechnology (Shanghai, China). The minimum detectable dose of mouse TNF-a, IL-6, IFN- $\beta$, CCL5, and IL-1 $\beta$ was typically less than $0.32 \mathrm{pg} / \mathrm{mL}, 0.56 \mathrm{pg} / \mathrm{mL}, 0.83 \mathrm{pg} / \mathrm{mL}, 0.12$ $\mathrm{pg} / \mathrm{mL}$, and $1.45 \mathrm{pg} / \mathrm{mL}$, respectively. Intra-assay and inter-assay precision of these ELISA kits was less than $6 \%$ and $9 \%$.

\section{Statistical Analysis}

Data in the "In-vitro Verification" section were presented as median ( $\min -\max$ ) and analyzed by SPSS Statistics v21 using Kruskal - Wallis $H$-test followed by posthoc tests. A p-value less than 0.05 was considered with statistical significance.

\section{Results}

\section{Characterization of Isatis Indigotica by UPLC-Q-TOF/MS}

The workflow of the current study is illustrated in Figure 1. Representative total ion current (TIC) chromatograms of the roots and leaves of $I i$, obtained by UPLCQ-TOF-MS in positive mode, are presented in Figure 2. As results, 73 peaks were detected and identified or putatively characterized from the leaf and root parts (Supplementary Table 1), which included 11 indoles and derivatives, 6 lignans, neolignans and related compounds, 5 quinolines and derivative, etc. Results showed that the chemical classifications of major components were similar between the leaves and roots. Moreover, the components in the leaves exhibited more structural diversity, which was in accordance with Chinese Pharmacopoeia.

\section{Prediction of Active Ingredients in li}

GI absorption and DL analysis were adopted to screen out the active ingredients of the herb using SwissADME. Notably, among all the components, indoles generally exceled in the GI absorption and the DL analysis. In addition, despite bad GI absorption, secoisolariciresinol diglucoside, ${ }^{32,33}$ and isovitexin ${ }^{34}$ were reported to possess high pharmacological activity, and therefore included in the subsequent network analysis. Seventeen active ingredients were ultimately selected (Table 1 and Figure 3).

\section{Construction of Herb-Ingredient-Target Network}

First, through searches on Swiss Target Prediction (swisstargetprediction.ch) ${ }^{31}$ and TCMSP databases, 218 targets were gathered for the 17 active ingredients, after duplicate deletion (Supplementary Table 2). The UniProt database was applied to get uniform gene symbols. Second, with the help of the Human Gene Database (GeneCards, genecards.org), ${ }^{35}$ the potential targets of the effective herbs were collected, using keywords related to anti-inflammatory and anti-viral processes. After duplicate removal, 14,287 and 19,975 targets were retained for the anti-inflammatory and anti-viral evaluation, respectively. The first 1000 targets with higher relevance scores for the herbal efficacy were preserved (Supplementary Tables 3 and 4). Third, overlapping targets that were connected to both the active ingredients and the herbal efficacy were screened out for the construction of the herb-active ingredient-target network. Presented in Figure 4A and B, 67 and 54 targets were used to conduct the next PPI analysis for the major hubs using the STRING database. Visualized by Cytoscape, 2 PPI networks were presented, with 67 nodes, 507 edges in anti-inflammation (Figure 4C), and 54 nodes, 509 edges in anti-virus (Figure 4D), followed by topological analysis. It was shown that major hubs included TNF, AKT1, SRC, IL2, CASP9, and CASP3 (Supplementary Tables 5 and 6). Finally, a herb-ingredient-target network of 36 nodes ( 1 herb, 14 ingredients, and 21 targets) and 49 edges was established (Figure 4E). Those components with a relatively high degree included indirubin, indigo, isatin, secoisolariciresinol, secoisolariciresinol diglucoside, and isovitexin. This indicated that a multi-component, and multi-target mechanism might participate in the exertion of the herbal efficacy. 


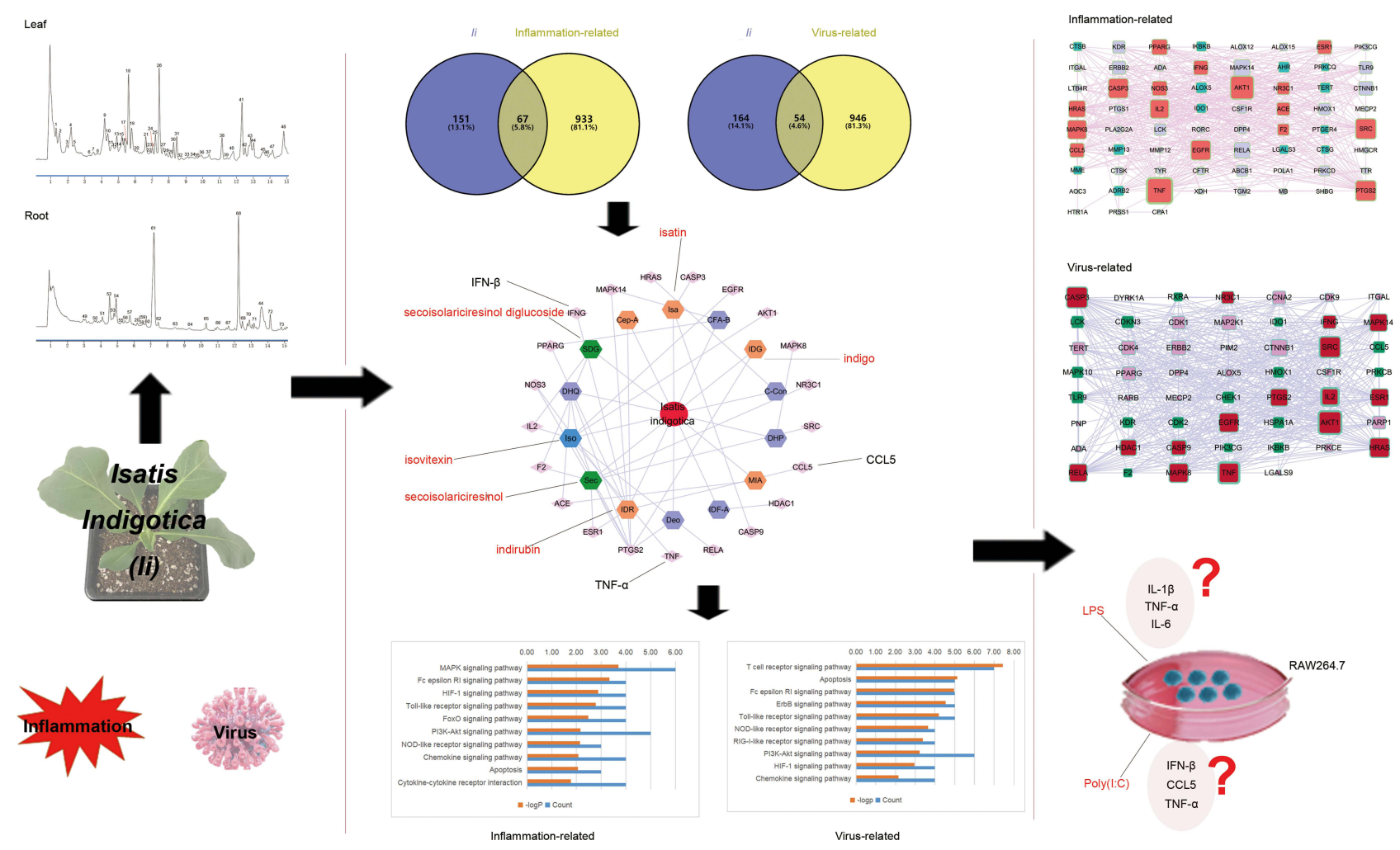

Figure I The work flow of the current study. The study aimed to propose a potential mechanism of the anti-inflammatory and anti-viral effects of li. A network analysisbased integrated strategy was exploited, with component identification of the herb through UPLC-Q-TOF-MS and in vitro verification.

\section{KEGG Pathway Enrichment}

To predict the potential-related pathways underlying the herbal efficacy, the 17 (anti-inflammation) and 16 (antivirus) key-related genes proposed by PPI analysis were introduced into the DAVID database (david.ncifcrf.gov/ ),${ }^{36}$ to conduct KEGG pathway enrichment. Under a threshold of $\mathrm{P} \leq 0.05,66$ and 80 pathways were found for the herbal anti-inflammatory and anti-viral effects, respectively. The top 10 related pathways are presented in Figure 5A and B. The closely related signal pathways included: MAPK signaling pathway, Fc epsilon RI signaling pathway, HIF-1 signaling pathway, Toll-like receptor signaling pathway, FoxO signaling pathway, PI3KAkt signaling pathway, NOD-like receptor signaling pathway, chemokine signaling pathway, apoptosis, cytokinecytokine receptor interaction, $\mathrm{T}$ cell receptor signaling pathway, ErbB signaling pathway, and RIG-I-like receptor signaling pathway. The potential underlying mechanisms of the herbal efficacy were visualized after manual analysis of the pathways in the KEGG database (kegg.jp). As shown in Figure 5, it was implied that the herbal efficacy was likely related to multi-component and multi- target mechanisms. Interestingly, isovitexin, a flavonoid, tended to participate in the inflammatory response, indoles were more likely to affect the cell proliferation processes, and lignans might have boarder bioactivity than other active ingredients.

\section{In-vitro Verification}

For the verification, 3 indoles, indirubin (IDR), indigo (IDG) and isatin (Isa), 2 lignans, secoisolariciresinol (Sec) and secoisolariciresinol diglucoside (SDG), and a flavonoid, isovitexin (Iso) were selected as representative compounds to be evaluated for their potential anti-inflammatory and anti-viral activity in vitro.

First, the cytotoxicity of the 6 compounds was examined in RAW264.7 cells through CCK-8 assays (Figure 6A-F). High cell viability $(>85 \%)$ was observed for all compounds at $20 \mu \mathrm{M}$, which was used as the incubating concentration for all subsequent experiments.

LPS (150 ng/mL) and Poly (I: C) $(50 \mu \mathrm{g} / \mathrm{mL})$ stimulated cell models were exploited to examine the antiinflammatory and anti-viral effects of the 6 

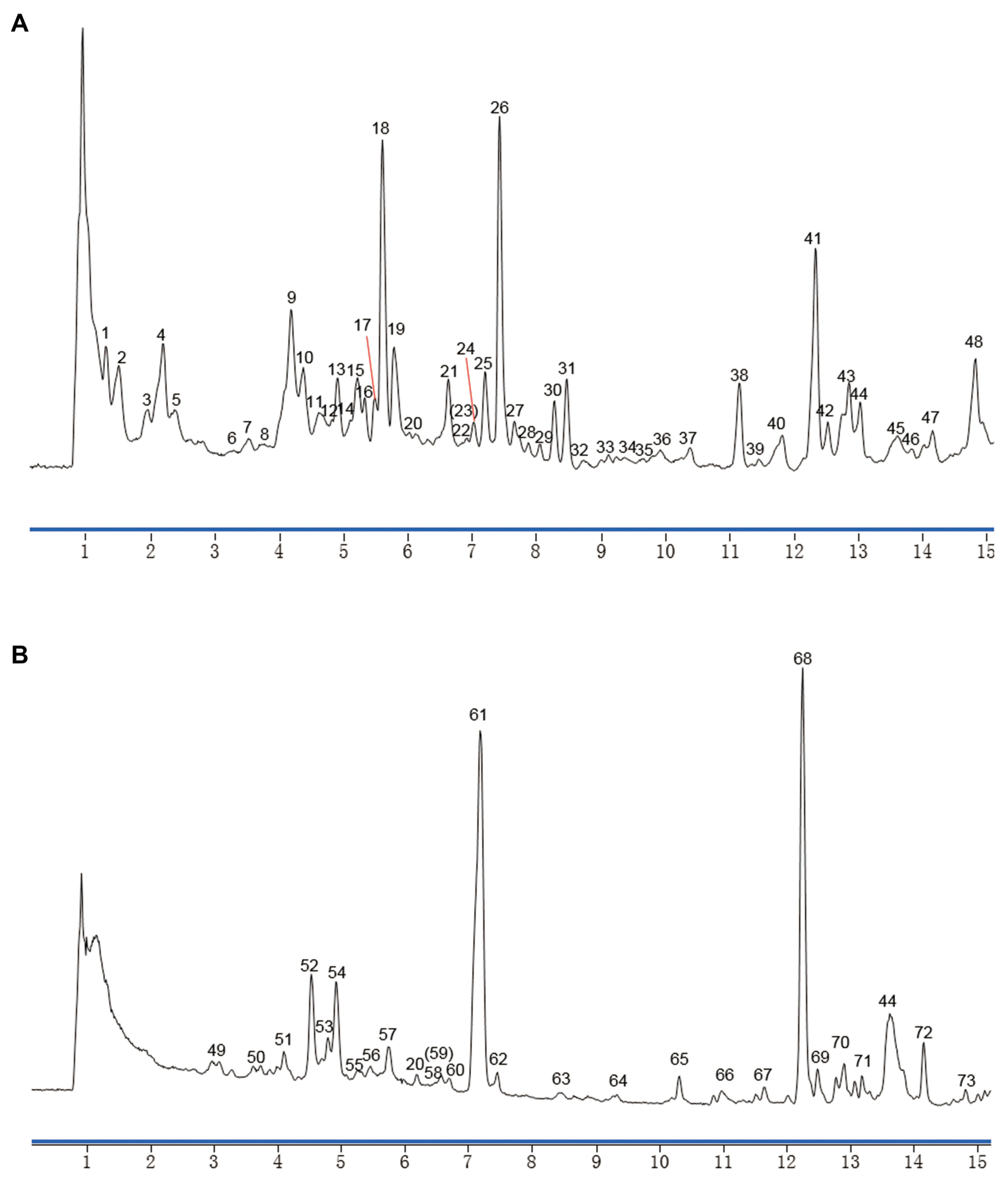

Figure 2 Identification of the main ingredients of li by UPLC-Q-TOF-MS. Representative TIC chromatograms of the extracts of the herbal leaves (A) and the roots (B) were presented.

representative compounds. ${ }^{37-39}$ We employed ELISA In the Poly (I: C)-incubated cell model, the expression of analysis to determine the levels of TNF-a, IL-6, IFN- $\beta$, IFN- $\beta$, CCL5, and TNF- $\alpha$ were significantly elevated CCL5, and IL-1 $\beta$.

(Figure 6G-I). Notably, indigo and secoisolariciresinol 
<smiles>O=C1C(c2[nH]c3ccccc3c2O)=Nc2ccccc21</smiles><smiles>Cc1cccc2c1-n1c(nc3ccccc3c1=O)C2(O)CC(=O)O</smiles><smiles>[R]OCC(CCC[CH])C(CO[R20])Cc1ccc(O)c(OC)c1</smiles>

(13)<smiles>COc1cc(/C=C/CO)ccc1OC1CCCCC1</smiles>

(16)<smiles>O=C1C(c2c(O)[nH]c3ccccc23)=Nc2ccccc21</smiles>

(5)<smiles>N#CCC1C(=O)Nc2cccc(O)c21</smiles>

(3)<smiles>O=C1Nc2ccccc2C1=O</smiles><smiles>COc1cc(Cl)cc2[nH]cc(CC(=O)O)c12</smiles><smiles>O=c1cc(-c2ccc(O)cc2)oc2cc(O)c(Cl)c(O)c12</smiles>

8) $\mathrm{R} 1=\mathrm{Glc}, \mathrm{R} 2=\mathrm{Glc}$

(12)

(11)<smiles>O=c1c2ccccc2nc2n1CCC2</smiles>

(14)<smiles>Cc1cccc2nc(CCCC(=O)O)[nH]c(=O)c12</smiles><smiles>CCC(O)C=CC=CC=CC(=O)CCCCCCCC(=O)O</smiles>

Figure 3 The structure information of 17 active compounds from li. 
Table I 17 Active Ingredients in Isatis Indigotica (li) Were Presented as Followed

\begin{tabular}{|c|c|c|c|c|c|c|c|}
\hline No. & Compounds & Acronym & CAS & $\begin{array}{l}\text { Molecular } \\
\text { Formulas }\end{array}$ & Category & GI* & $\mathbf{D L}^{\#}$ \\
\hline I & Indigo & IDG & $482-89-3$ & $\mathrm{C}_{16} \mathrm{H}_{10} \mathrm{~N}_{2} \mathrm{O}_{2}$ & Indoles & High & $5 \mathrm{Yes}^{\dagger}$ \\
\hline 2 & Indirubin & IDR & $479-4 \mid-4$ & $\mathrm{C}_{16} \mathrm{H}_{10} \mathrm{~N}_{2} \mathrm{O}_{2}$ & Indoles & High & 5 Yes \\
\hline 3 & Isatin & Isa & $9 \mid-56-5$ & $\mathrm{C}_{8} \mathrm{H}_{5} \mathrm{NO}_{2}$ & Indoles & High & 3 Yes \\
\hline 4 & Cephalanthrin A & Cep-A & $1829563-08-7$ & $\mathrm{C}_{17} \mathrm{H}_{12} \mathrm{~N}_{2} \mathrm{O}_{4}$ & Indoles & High & 5 Yes \\
\hline 5 & (IH-indol-3-yl)oxoacetamide & IOA & |380540-77-| & $\mathrm{C}_{10} \mathrm{H}_{8} \mathrm{~N}_{2} \mathrm{O}_{2}$ & Indoles & High & 4 Yes \\
\hline 6 & I-methoxy-3-indoleacetic acid & MIA & $134792-52-2$ & $\mathrm{C}_{11} \mathrm{H}_{11} \mathrm{NO}_{3}$ & Indoles & High & 5 Yes \\
\hline 7 & Secoisolariciresinol & $\mathrm{Sec}$ & $29388-59-8$ & $\mathrm{C}_{20} \mathrm{H}_{26} \mathrm{O}_{6}$ & Lignans & High & 5 Yes \\
\hline 8 & Secoisolariciresinol diglucoside & SDG & | 589932-33-3 & $\mathrm{C}_{32} \mathrm{H}_{46} \mathrm{O}_{16}$ & Lignans & Low & 0 Yes \\
\hline 9 & Isovitexin & Iso & $38953-85-4$ & $\mathrm{C}_{21} \mathrm{H}_{20} \mathrm{O}_{10}$ & Flavonoids & Low & I Yes \\
\hline 10 & 4(IH)-quinolone-3-carboxylic acid & QCA & $|372|-0 \mid-2$ & $\mathrm{C}_{10} \mathrm{H}_{7} \mathrm{NO}_{3}$ & Others & High & 4 Yes \\
\hline 11 & Deoxyvasicinone & Deo & $530-53-0$ & $\mathrm{C}_{11} \mathrm{H}_{10} \mathrm{~N}_{2} \mathrm{O}$ & Others & High & 4 Yes \\
\hline 12 & 2-amino-I-(4-hydroxy-3-methoxyphenyl)propane-I,3-diol & AHP & $50731-36-7$ & $\mathrm{C}_{10} \mathrm{H}_{15} \mathrm{NO}_{4}$ & Others & High & 4 Yes \\
\hline 13 & Cis-coniferin & C-Con & $531-29-3$ & $\mathrm{C}_{16} \mathrm{H}_{22} \mathrm{O}_{8}$ & Others & High & 4 Yes \\
\hline 14 & 4-(4-oxo-3,4-dihydroquinazolin-2-yl)butanoic acid & $\mathrm{DHQ}$ & $95494-5 I-2$ & $\mathrm{C}_{12} \mathrm{H}_{12} \mathrm{~N}_{2} \mathrm{O}_{3}$ & Others & High & 5 Yes \\
\hline 15 & $\begin{array}{c}\text { 2,3-dihydro-I } \mathrm{H} \text {-pyrrolo }[2, \mathrm{I}-\mathrm{Cl}[\mathrm{I}, 4] \text { benzodiazepine- } \\
5, \mathrm{II}(\mathrm{IOH}, \mathrm{IIH}) \text {-dione }]\end{array}$ & $\mathrm{DHP}$ & | 8877-34-4 & $\mathrm{C}_{12} \mathrm{H}_{12} \mathrm{~N}_{2} \mathrm{O}_{2}$ & Others & High & 5 Yes \\
\hline 16 & Corchorifatty acid B & CFA-B & $147383-02-6$ & $\mathrm{C}_{18} \mathrm{H}_{28} \mathrm{O}_{4}$ & Others & High & 4 Yes \\
\hline 17 & Indiforine A & IDF-A & $2249831-92-1$ & $\mathrm{C}_{15} \mathrm{H}_{15} \mathrm{NO}_{7}$ & Others & High & 4 Yes \\
\hline
\end{tabular}

Notes: ${ }^{*} \mathrm{Gl}$ means gastrointestinal absorption in Pharmacokinetics analysis, obtained from SwissADME. \#DL means Druglikeness analysis obtained from SwissADME, including Lipinski (Pfizer), Ghose, Veber (GSK), Egan (Pharmacia), and Muegge (Bayer) rules. ${ }^{\dagger}$ The numbers in the DL mean how many times "Yes; 0 violations" has appeared in Lipinski 5 rules.

diglucoside treatment at $20 \mu \mathrm{M}$ could markedly reduce expression of TNF- $\alpha$ in Poly (I: C)-incubated cells (Poly (I: C) + IDG group 183.59 (164.42-200.82), Poly (I: C) + SDG group 181.19 (162.07-210.70) vs Poly (I: C) group 283.74 (220.88-303.24)). In fact, other compounds treatment also slightly decreased the expression of IFN- $\beta$, CCL5, and TNF- $\alpha$.

In the LPS-stimulated cell model, the expression of TNF- $\alpha$, IL-1 $\beta$, and IL-6 was significantly increased (Figure 6J-L). Compared to the LPS group, isovitexin treatment significantly reduced TNF- $\alpha$ expression (LPS + Iso group 131.23 (115.26-138.93) vs LPS group 156.47 (147.51-196.10)). In addition, IL-1 $\beta$ expression could also be significantly inhibited by isatin treatment (LPS + Isa group 1.52 (1.15-2.26) vs LPS group 2.70 (2.48-3.06)).

\section{Discussion}

Using a network pharmacology-based integrated approach with UPLC-Q-TOF-MS and in vitro verification, the possible mechanisms underlying the anti-inflammatory and anti-viral effects of $I i$ are proposed in Figure 5C. The elucidation of the efficacy of herbs would largely facilitate the research and development of possible new medications.

Natural products could make a reservoir for drug discovery and development. For example, essential oils were recently reported to hold potential anti-microbial bioactivities. ${ }^{40-44}$ Thus, chemical characterization of antipyretic detoxicate crude drugs could markedly facilitate the discovery of related novel compounds. Here, the characterization of $I i$ by UPLC-Q-TOF-MS showed that the chemical composition in the leaves was more diverse than that in the roots, which might be the reason for which a larger proportion of $F$ Isatidis comprises the Compound Banlangen Granules ( $R$ Isatidis vs $F$ Isatidis $=2: 3$ ). A group of compounds with potential antiinflammatory and anti-viral effects were spotted. For example, our network analysis and in vitro bioassay analysis both screened isovitexin out as an active compound to inhibit possible inflammatory cascades, protecting organisms from unnecessary injury. A previous report also showed that isovitexin treatment considerably inhibited the production of cytokines, such as TNF- $\alpha$ and IL$6 .^{23}$ It has also been suggested that isovitexin could be effective against other diseases related to the cardiovascular and endocrine systems. ${ }^{34}$ Moreover, indoles were pharmacological active in the regulation of proinflammatory factors and cell proliferation. It has been suggested that indoles might be an interspecies and interkingdom signaling molecule, ${ }^{45}$ hinting at the possible strong potency of their anti-microbial roles. Lignans 
A

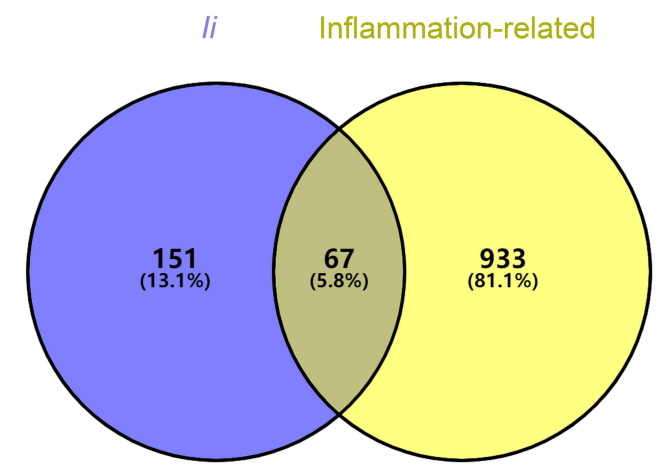

C
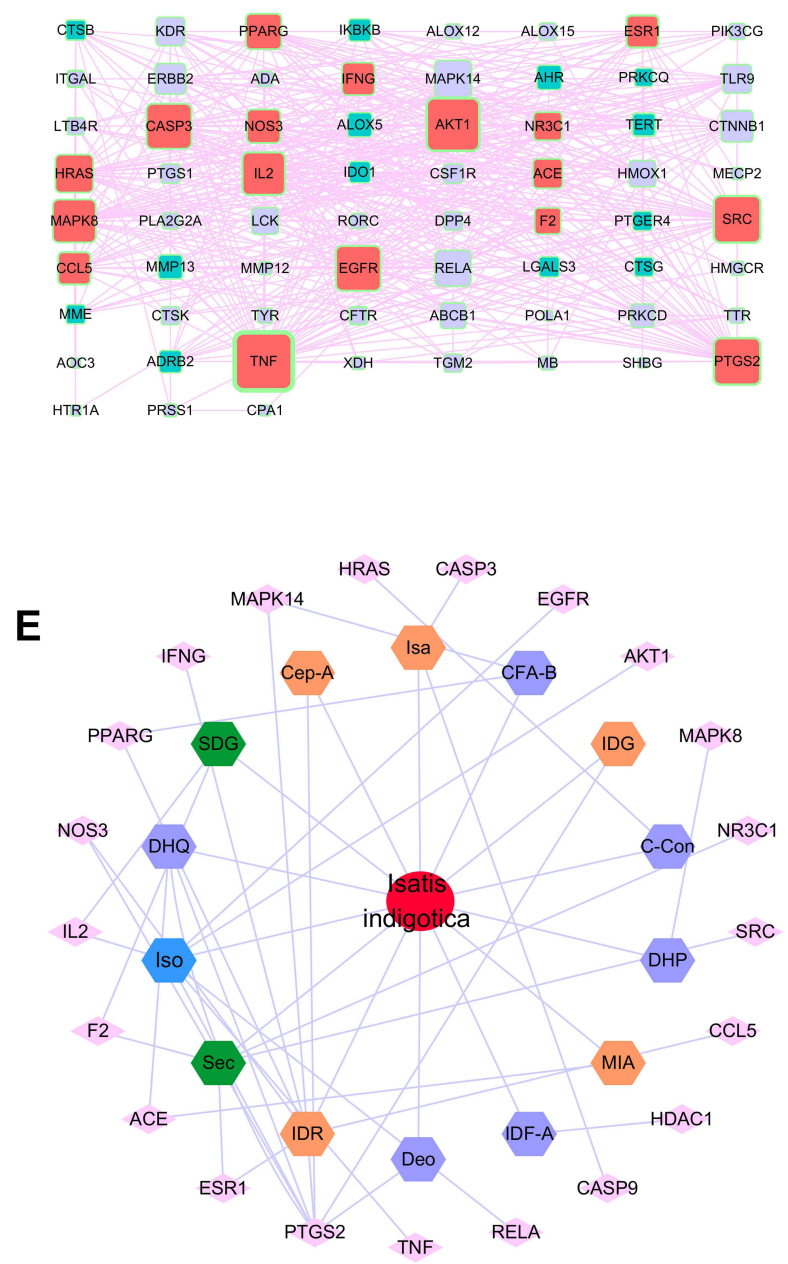

B

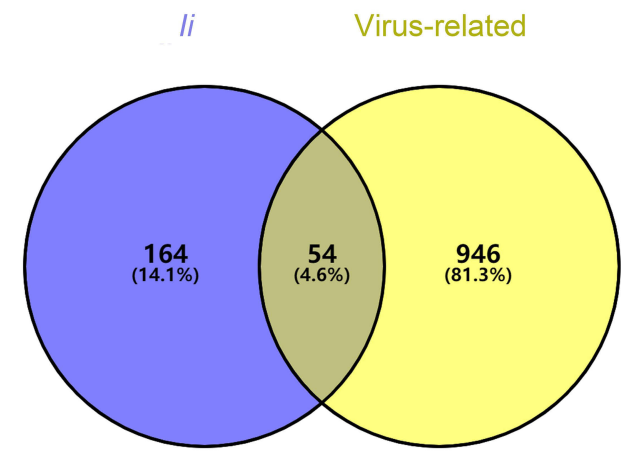

D

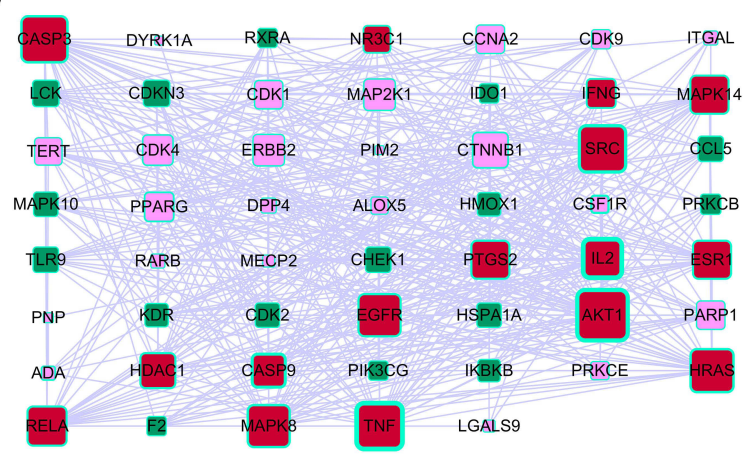

Figure 4 Venn diagram of li and anti-inflammatory (A)/anti-viral (B). Major hubs were screened through PPI analysis for anti-inflammatory (C) and anti-viral (D) effects of the herb. A herb-active ingredient-target network was finally constructed (E).

showed a relatively weak effect in our subsequent verification. Our network analysis showed that secoisolariciresinol and its diglucoside might have a wider effect in these targets. Sowndhararajan et al suggested that lignans might have the potential to treat various neurodegenerative diseases. ${ }^{46}$ Aqeel et al reported that secoisolariciresinol diglucoside could be used as a therapeutic agent against nephrotoxicity caused by cadmium, by acting as a natural supramolecular binding component to chelate metal cations. ${ }^{26}$ 
A

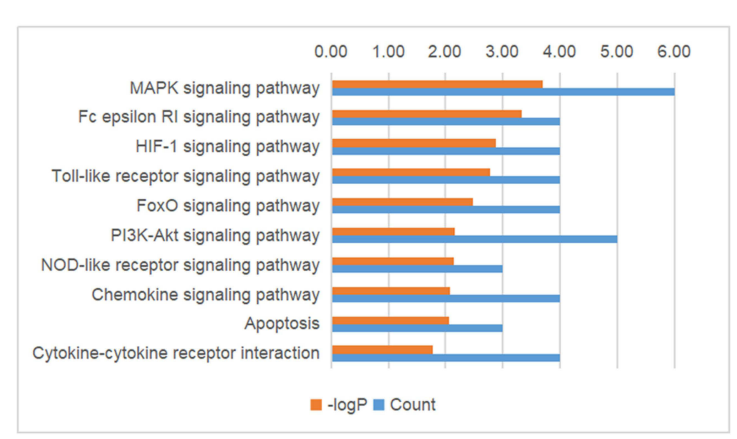

B

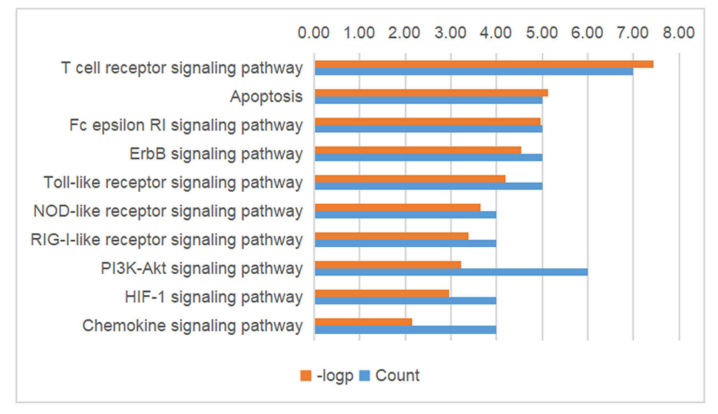

C

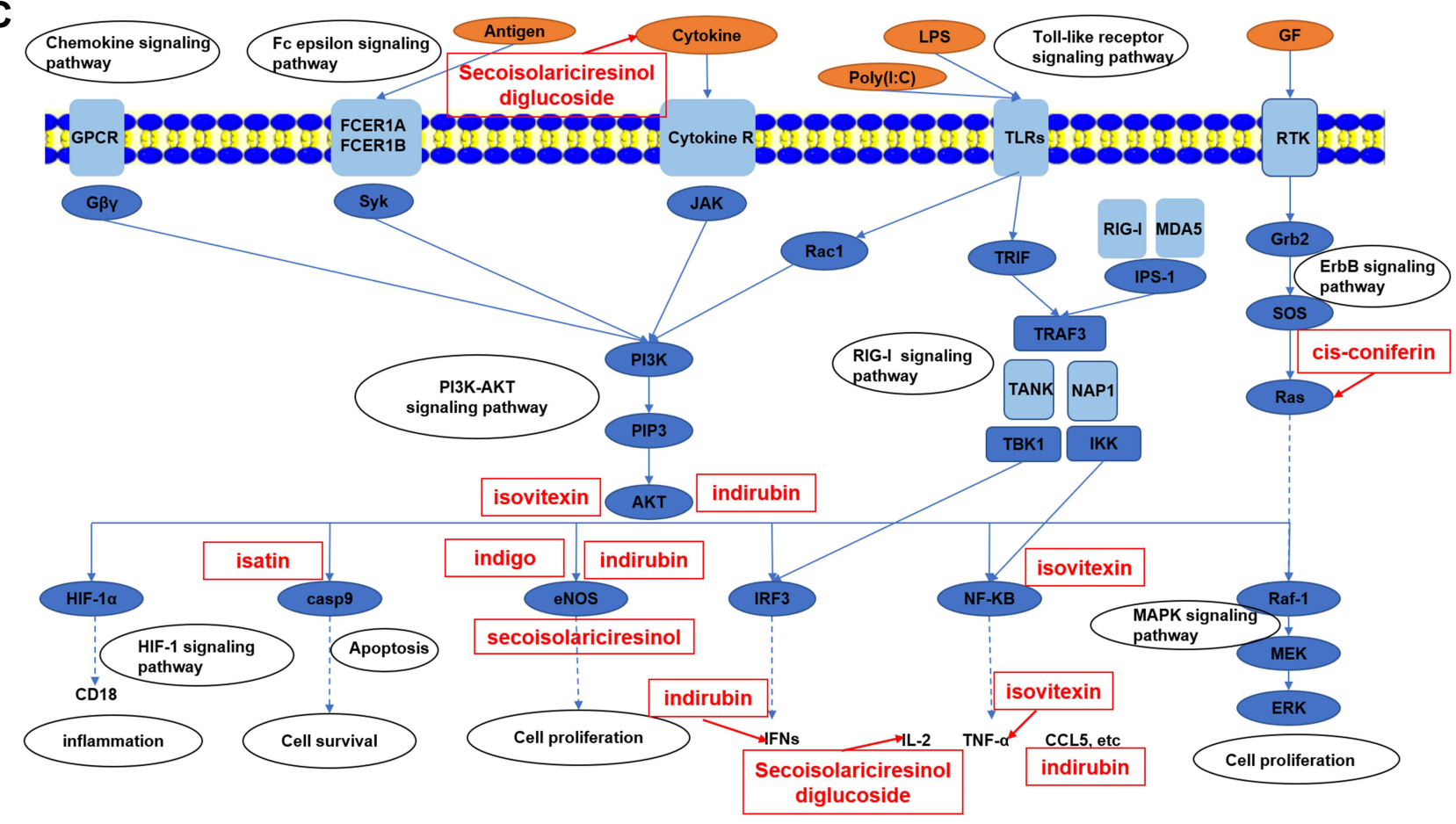

Figure 5 The top 10 related pathways to the herbal anti-inflammatory $(\mathbf{A})$ and anti-viral (B) effects. Multiple-component, multi-target, and multi-pathway mechanisms of the herbal efficacy were proposed and illustrated $(\mathbf{C})$.

It has been shown that indirubin $(100 \mu \mathrm{M}$ and $200 \mu \mathrm{M})$ reduced RANTES (CCL5) production in influenza A/ NWS/33-infected H292 cells. $^{47}$ In our study, indirubin $(20 \mu \mathrm{M})$ did not significantly reduce the expression of CCL5, possibly due to the relatively lower incubation concentration of the compound. Type I interferons (IFNs), the frontline factors against viruses, play key roles initiating host anti-viral responses. ${ }^{48}$ Our results also showed that indigo, isatin, and isovitexin repressed IFN- $\beta$ production in RAW264.7 cells induced by poly (I: C) without significant difference. As predicted by network pharmacological analysis, we hypothesized that these active ingredients inhibited IFN- $\beta$ production possibly through the RIG-I signaling pathway, although further research is necessary. The uncontrolled, strong cytokine production, known as a "cytokine storm," is thought to stimulate severe systemic inflammation in response to various infections. Hence, it is vital to develop therapies that suppress virus-induced hyper-inflammation. ${ }^{49}$ In our study, we speculated that indirubin, indigo, isatin, secoisolariciresinol diglucoside, and isovitexin might contribute to the herbal efficacy of $I i$, possibly by reducing the levels of cytokines and chemokines, such as CCL5 and IFN- $\beta$, and thus inhibiting viral inflammation.

Our results showed that numerous crosslinks existed between the anti-inflammatory and anti-viral effects of $I i$. 

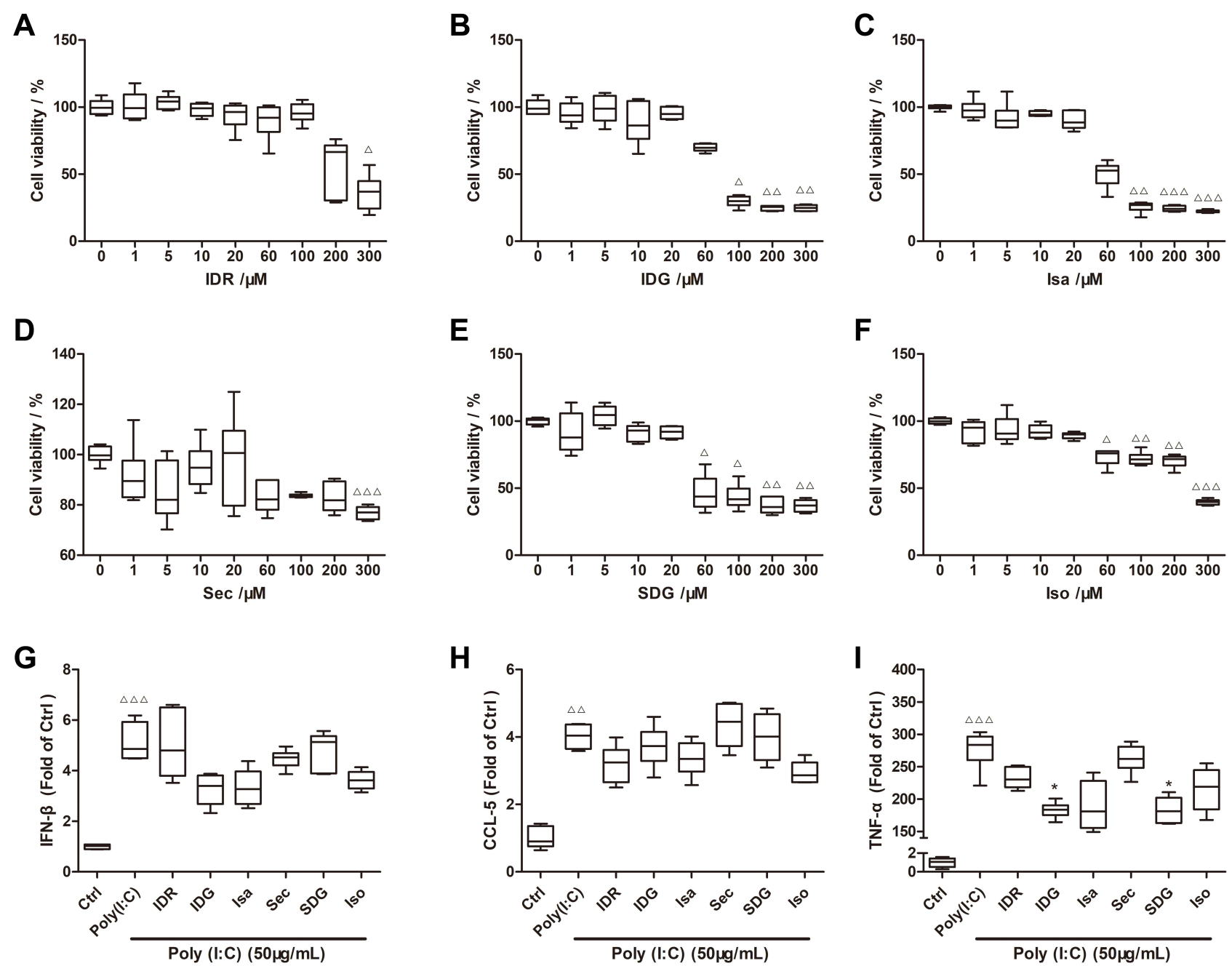

\section{$\mathbf{J}$}

\section{K}
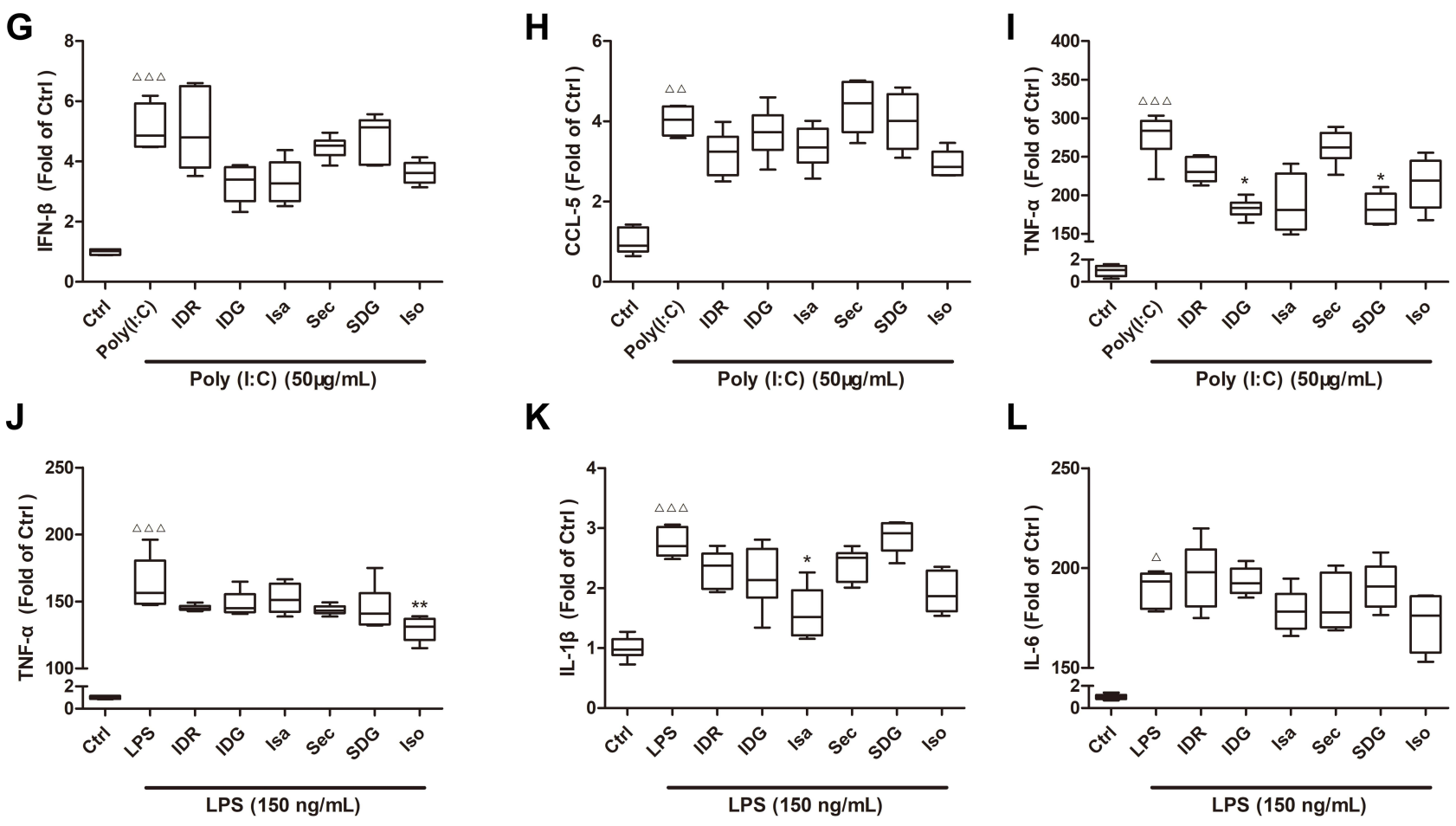

$\mathbf{L}$

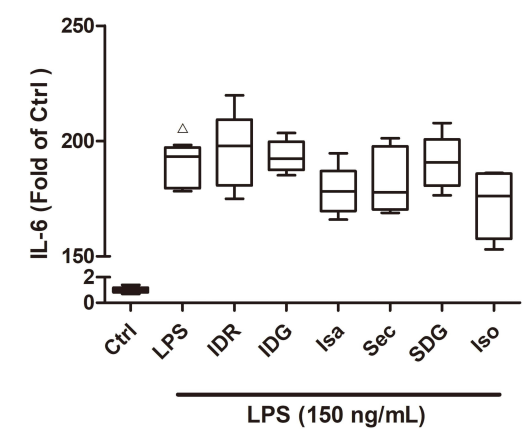

Figure 6 The cytotoxicity of the 6 ingredients was illustrated, respectively (A-F). The effects of the representative ingredients on Poly (I: C) (G-I) and LPS (J-L) treated RAW 264.7 cells were presented. Results were presented as median (min - max). $n=6 ;{ }^{\Delta} p<0.05,{ }^{\Delta \Delta} p<0.01,{ }^{\Delta \Delta \Delta} p<0.00$ I vs Control group; ${ }^{*} p<0.05$, ** ${ }^{*}<0.01$, vs Poly (l: C) or LPS group.The top 10 related pathways to the herbal anti-inflammatory (A) and anti-viral (B) effects. Multiple-component, multi-target, and multi-pathway mechanisms of the herbal efficacy were proposed and illustrated (C).

A large portion of key pathways and targets have been shown to be involved in herbal efficacy, such as chemokine signaling pathway, Fc epsilon signaling pathway, Toll-like receptor signaling pathway, and PI3K-AKT signaling pathway. The T cell receptor signaling pathway and RIG-I-like receptor signaling pathway play an important role in the body's resistance to viral infections. ${ }^{50} \mathrm{Xu}$ et al highlighted the RIG-I-like signaling pathway as a possibly important pathway in the protective effect of $R$ Isatidis extract in a mouse model of respiratory syncytial virus infection. ${ }^{51}$ The PI3K-AKT signaling pathway 
is activated by many types of cellular stimuli or toxic insults and regulates fundamental cellular functions such as transcription, translation, proliferation, growth, and survival. A heatclearing or antipyretic herb couple, Radix Scutellariae and Rhizoma Coptidis, were reported to regulate PI3K-AKT signaling pathway. ${ }^{52}$ Toll-like receptors (TLRs) are specific families of pattern recognition receptors, which are responsible for detecting microbial pathogens and generating innate immune responses. The anti-inflammatory effect of the aforementioned herb couple has been reported to be involved with the TLR4 signaling pathway. ${ }^{53}$

The balance between inflammatory and immune responses might also be of great importance in exertion of the herbal efficacy and cytosolic sensing of viruses. ${ }^{50}$ Allogenous pathogens, such as viruses, can induce inflammation and innate or acquired immune responses. ${ }^{54}$ While immune defenses are vital to kill pathogens, the inflammatory cascade had to be avoided to protect the organism. This kind of balance can be seen in certain targets in a manner of positive or negative feedback. For example, the kinase receptor-interacting serine/threonine-protein kinase 1 (RIP1) is crucial for programmed necrosis, a form of caspase-independent cell death, but also mediates activation of the pro-survival transcription factor NF$\kappa \mathrm{B}$. Other vital biological processes such as autophagy, could balance the beneficial and detrimental effects of immunity and inflammation, thereby protecting against infectious, autoimmune and inflammatory diseases. ${ }^{55}$

\section{Conclusion}

In conclusion, the current study revealed that as the pharmacodynamics material basis of $I i$, indoles, lignans, and flavonoids are involved in the herbal efficacy of $I i$ through different aspects. Certain compounds in Ii might be worth our attention, including indirubin, indigo, isatin, secoisolariciresinol diglucoside, and isovitexin. Multiple signaling pathways were involved in the exertion of the herbal efficacy of $I$, including PI3K-AKT signaling pathway, RIG-I signaling pathway, ErbB signaling pathway, MAPK signaling pathway, etc. Further in-depth studies are still needed.

\section{Author Contributions}

All authors made substantial contributions to the conception and design, acquisition of data, or analysis and interpretation of data; took part in drafting the article or revising it critically for important intellectual content; agreed to submit to the current journal; gave final approval of the version to be published; and agree to be accountable for all aspects of the work.

\section{Funding}

This research was funded by National Key R\&D Program of China (grant 2018YFC1707304), Natural Science Foundation of China (grant 81903745), Shanghai Pujiang Program (grant 19PJ1409300) and the Key Project at the central government level: The ability establishment of sustainable use for valuable Chinese medicine resources (grant 2060302).

\section{Disclosure}

The authors report no conflicts of interest in this work.

\section{References}

1. Zhao YL, Wang JB, Shan LM, Jin C, Ma L, Xiao XH. Effect of Radix isatidis polysaccharides on immunological function and expression of immune related cytokines in mice. Chin $J$ Integr Med. 2008;14(3):207-211. doi:10.1007/s11655-008-0207-2

2. Chan YS, Cheng LN, Wu JH, et al. A review of the pharmacological effects of Arctium lappa (burdock). Inflammopharmacology. 2011;19 (5):245-254. doi:10.1007/s10787-010-0062-4

3. Hu N, Wang C, Dai X, et al. Phillygenin inhibits LPS-induced activation and inflammation of LX2 cells by TLR4/MyD88/ NF-kappaB signaling pathway. J Ethnopharmacol. 2020;248:11 2361. doi:10.1016/j.jep.2019.112361

4. Liu JF, Jiang ZY, Wang RR, et al. Isatisine A, a novel alkaloid with an unprecedented skeleton from leaves of Isatis indigotica. Org Lett. 2007;9(21):4127-4129. doi:10.1021/o1701540y

5. Zhou W, Zhang XY. Research progress of Chinese herbal medicine Radix isatidis (banlangen). Am J Chin Med. 2013;41(4):743-764. doi:10.1142/S0192415X1350050X

6. Ho YL, Chang YS. Studies on the antinociceptive, anti-inflammatory and anti pyretic effects of Isatis indigotica root. Phytomedicine. 2002;9(5):419-424. doi:10.1078/09447110260571661

7. Nie LX, Wu YL, Dai Z, Ma SC. Antiviral activity of Isatidis Radix derived glucosinolate isomers and their breakdown products against influenza A in vitro/ovo and mechanism of action. $J$ Ethnopharmacol. 2020;251:112550. doi:10.1016/j.jep.2020.112550

8. Yan J, Liu S, Li BP, Liu ZQ, Guo DF. Fingerprint chromatograms and chemical components of compound indigowoad root granule by APCI-MS and LC-APCI-MS. J Chin Mass Spectromet Soc. 2017;38 (3):320-327. doi:10.7538/zpxb.youxian.2016.0057

9. Shin EK, Kim DH, Lim H, Shin HK, Kim JK. The anti-inflammatory effects of a methanolic extract from Radix Isatidis in murine macrophages and mice. Inflammation. 2010;33(2):110-118. doi:10.1007/ s10753-009-9164-9

10. Li Z, Li L, Zhou H, et al. Radix isatidis polysaccharides inhibit influenza a virus and influenza A virus-induced inflammation via suppression of host TLR3 signaling in vitro. Molecules. 2017;22(1). doi:10.3390/molecules22010116

11. Ruan D, Liu W, Shi Y, et al. Protective effects of aqueous extract of radix isatidis on lipopolysaccharide-induced sepsis in C57BL/6J mice. J Med Food. 2020;23(1):79-89. doi:10.1089/jmf.2019.4476

12. Xiao $P$, Huang H, Chen J, Li X. In vitro antioxidant and anti-inflammatory activities of Radix Isatidis extract and bioaccessibility of six bioactive compounds after simulated gastro-intestinal digestion. J Ethnopharmacol. 2014;157:55-61. doi:10.1016/j.jep.2014.09.005

13. Jiang L, Lu Y, Jin J, et al. n-Butanol extract from Folium isatidis inhibits lipopolysaccharide-induced inflammatory cytokine production in macrophages and protects mice against lipopolysaccharide-induced endotoxic shock. Drug Des Devel Ther. 2015;9:5601-5609. doi:10.2147/DDDT.S89924 
14. Yang Z-F, Wang Y-T, Qin S, et al. The effects of a hot water soluble extract (S-03) isolated from Isatis indigotica Root on Influenza A and B viruses in vitro. Chin J Virol. 2011;27(3):6.

15. Zhang CE, Xiong Y, Dong Q, et al. Comparison of reversed-phase liquid chromatography and hydrophilic interaction chromatography for the fingerprint analysis of Radix isatidis. J Sep Sci. 2014;37(910):1141-1147. doi:10.1002/jssc.201301159

16. He LW, Liu HQ, Chen YQ, Yang JY, Wang TL, Li W. Total synthesis and anti-viral activities of an extract of Radix isatidis. Molecules. 2014;19(12):20906-20912. doi:10.3390/molecules191220906

17. Wang XL, Chen MH, Wang F, et al. [Chemical consitituents from root of Isatis indigotica]. Zhongguo Zhong Yao Za Zhi. 2013;38 (8):1172-1182. Chinese.

18. Wang T, Wang X, Zhuo Y, et al. Antiviral activity of a polysaccharide from Radix Isatidis (Isatis indigotica Fortune) against hepatitis $B$ virus (HBV) in vitro via activation of JAK/STAT signal pathway. J Ethnopharmacol. 2020;257:112782. doi:10.1016/j.jep.2020.112782

19. Deng YP, Liu YY, Liu Z, et al. Antiviral activity of Folium isatidis derived extracts in vitro and in vivo. Am J Chin Med. 2013;41 (4):957-969. doi:10.1142/S0192415X1350064X

20. Li B, Chen WS, Zhang HM, Zhang WD, Yang GJ, Qiao CZ. [A new alkaloids isolated from tetraploidy banlangen]. Yaо Хие Хие Ваo. 2003;38(6):430-432. Chinese.

21. Shi Y, Zheng C, Li J, Yang L, Wang Z, Wang R. Separation and quantification of four main chiral glucosinolates in radix isatidis and its granules using high-performance liquid chromatography/diode array detector coupled with circular dichroism detection. Molecules. 2018;23(6):1305. doi:10.3390/molecules23061305

22. Hou X, Zhang X, Bi J, Zhu A, He L. Indole-3-carboxaldehyde regulates RSV-induced inflammatory response in RAW264.7 cells by moderate inhibition of the TLR7 signaling pathway. $\mathrm{J} \mathrm{Nat} \mathrm{Med}$. 2021;75:602-611. doi:10.1007/s11418-021-01506-0

23. Lv H, Yu Z, Zheng Y, et al. Isovitexin exerts anti-inflammatory and anti-oxidant activities on lipopolysaccharide-induced acute lung injury by inhibiting MAPK and NF-kappaB and activating HO-1/Nrf2 pathways. Int J Biol Sci. 2016;12(1):72-86. doi:10.7150/ijbs.13188

24. Xiao $\mathrm{H}, \mathrm{Xu}$ J. Isaindigotone as an inhibitor of the lipopolysaccharide induced inflammatory reaction of BV2 cells and corresponding mechanisms. Mol Med Rep. 2019;19(4):2890-2896. doi:10.3892/ mmr.2019.9909

25. Zhang $\mathrm{X}$, Song $\mathrm{Y}, \mathrm{Wu} \mathrm{Y}$, et al. Indirubin inhibits tumor growth by antitumor angiogenesis via blocking VEGFR2-mediated JAK/STAT3 signaling in endothelial cell. Int J Cancer. 2011;129(10):2502-2511. doi:10.1002/ijc.25909

26. Aqeel T, Gurumallu SC, Bhaskar A, Hashimi SM, Javaraiah R. Secoisolariciresinol diglucoside protects against cadmium-induced oxidative stress-mediated renal toxicity in rats. $J$ Trace Elem Med Biol. 2020;61:126552. doi:10.1016/j.jtemb.2020.126552

27. Hopkins AL. Network pharmacology. Nat Biotechnol. 2007;25 (10):1110-1111. doi:10.1038/nbt1007-1110

28. Seeley JJ, Ghosh S. Molecular mechanisms of innate memory and tolerance to LPS. J Leukoc Biol. 2017;101(1):107-119. doi:10.1189/ jlb.3MR0316-118RR

29. Hafner AM, Corthesy B, Merkle HP. Particulate formulations for the delivery of poly(I:C) as vaccine adjuvant. Adv Drug Deliv Rev. 2013;65(10):1386-1399. doi:10.1016/j.addr.2013.05.013

30. Daina A, Michielin O, Zoete V. SwissADME: a free web tool to evaluate pharmacokinetics, drug-likeness and medicinal chemistry friendliness of small molecules. Sci Rep. 2017;7:42717. doi:10. 1038/srep42717

31. Daina A, Michielin O, Zoete V. SwissTargetPrediction: updated data and new features for efficient prediction of protein targets of small molecules. Nucleic Acids Res. 2019;47(W1):W357-W364. doi:10. 1093/nar/gkz382
32. Pietrofesa RA, Woodruff P, Hwang WT, et al. The synthetic lignan secoisolariciresinol diglucoside prevents asbestos-induced NLRP3 inflammasome activation in murine macrophages. Oxid Med Cell Longev. 2017;2017:7395238. doi:10.1155/2017/7395238

33. Chhillar H, Chopra P, Ashfaq MA. Lignans from linseed (Linum usitatissimum L.) and its allied species: retrospect, introspect and prospect. Crit Rev Food Sci Nutr. 2020;1-23. doi:10.1080/ 10408398.2020.1784840

34. He M, Min JW, Kong WL, He XH, Li JX, Peng BW. A review on the pharmacological effects of vitexin and isovitexin. Fitoterapia. 2016;115:74-85. doi:10.1016/j.fitote.2016.09.011

35. Stelzer G, Rosen N, Plaschkes I, et al. The GeneCards suite: from gene data mining to disease genome sequence analyses. Curr Protoc Bioinformatics. 2016;54:1 30 1-1 30 33. doi:10.1002/cpbi.5

36. Huang da W, Sherman BT, Lempicki RA. Systematic and integrative analysis of large gene lists using DAVID bioinformatics resources. Nat Protoc. 2009;4(1):44-57. doi:10.1038/nprot.2008.211

37. Fujihara M, Muroi M, Tanamoto K, Suzuki T, Azuma H, Ikeda H. Molecular mechanisms of macrophage activation and deactivation by lipopolysaccharide: roles of the receptor complex. Pharmacol Ther. 2003;100(2):171-194. doi:10.1016/j. pharmthera.2003.08.003

38. Lee HN, Shin SA, Choo GS, et al. Anti-inflammatory effect of quercetin and galangin in LPS-stimulated RAW264.7 macrophages and DNCB-induced atopic dermatitis animal models. Int J Mol Med. 2018;41(2):888-898. doi:10.3892/ijmm.2017.3296

39. Hasan M, Ruksznis C, Wang Y, Leifer CA. Antimicrobial peptides inhibit polyinosinic-polycytidylic acid-induced immune responses. J Immunol. 2011;187(11):5653-5659. doi:10.4049/jimmunol.1102144

40. Tariq S, Wani S, Rasool W, et al. A comprehensive review of the antibacterial, antifungal and antiviral potential of essential oils and their chemical constituents against drug-resistant microbial pathogens. Microb Pathog. 2019;134:103580. doi:10.1016/j.micpath. 2019.103580

41. Trong Le N, Viet Ho D, Quoc Doan T, et al. In vitro antimicrobial activity of essential oil extracted from leaves of leoheo domatiophorus Chaowasku, D.T. Ngo and H.T. Le in Vietnam. Plants (Basel). 2020;9(4). doi:10.3390/plants9040453

42. Trong Le N, Viet Ho D, Quoc Doan T, et al. Biological activities of essential oils from leaves of Paramignya trimera (Oliv.) guillaum and Limnocitrus littoralis (Miq.) swingle. Antibiotics (Basel). 2020;9(4). doi:10.3390/antibiotics9040207

43. Sanna G, Madeddu S, Serreli G, et al. Antiviral effect of Hornstedtia bella Skornick essential oil from the whole plant against vaccinia virus (VV). Nat Prod Res. 2020;1-7. doi:10.1080/14786419. 2020.1824228 .

44. Le NT, Donadu MG, Ho DV, et al. Biological activities of essential oil extracted from leaves of Atalantia sessiflora Guillauminin Vietnam. J Infect Dev Ctries. 2020;14(9):1054-1064. doi:10.3855/ jidc. 12469

45. Lee JH, Wood TK, Lee J. Roles of indole as an interspecies and interkingdom signaling molecule. Trends Microbiol. 2015;23 (11):707-718. doi:10.1016/j.tim.2015.08.001

46. Sowndhararajan K, Deepa P, Kim M, Park SJ, Kim S. An overview of neuroprotective and cognitive enhancement properties of lignans from Schisandra chinensis. Biomed Pharmacother. 2018;97:958-968. doi:10.1016/j.biopha.2017.10.145

47. Mak NK, Leung CY, Wei XY, et al. Inhibition of RANTES expression by indirubin in influenza virus-infected human bronchial epithelial cells. Biochem Pharmacol. 2004;67(1):167-174. doi:10.1016/j. bcp.2003.08.020

48. Chen K, Xiao F, Hu D, et al. SARS-CoV-2 nucleocapsid protein interacts with RIG-I and represses RIG-mediated IFN-beta production. Viruses. 2020;13(1):47. doi:10.3390/v13010047 
49. Tisoncik JR, Korth MJ, Simmons CP, Farrar J, Martin TR, Katze MG. Into the eye of the cytokine storm. Microbiol Mol Biol Rev. 2012;76(1):16-32. doi:10.1128/MMBR.05015-11

50. Goubau D, Deddouche S, Sousa CRE. Cytosolic sensing of viruses. Immunity. 2013;38(5):855-869. doi:10.1016/j.immuni.20 13.05 .007

51. Xu H, He L, Chen J, et al. Different types of effective fractions from Radix Isatidis revealed a multiple-target synergy effect against respiratory syncytial virus through RIG-I and MDA5 signaling pathways, a pilot study to testify the theory of superposition of traditional Chinese Medicine efficacy. J Ethnopharmacol. 2019;239:111901. doi:10.1016/j.jep.2019.111901

52. Cui X, Qian DW, Jiang S, Shang EX, Zhu ZH, Duan JA. Scutellariae radix and coptidis rhizoma improve glucose and lipid metabolism in T2DM rats via regulation of the metabolic profiling and MAPK/ PI3K/Akt signaling pathway. Int J Mol Sci. 2018;19(11):3634. doi:10.3390/ijms19113634
53. Zhang $\mathrm{CH}$, Sheng JQ, Sarsaiya $\mathrm{S}$, et al. The anti-diabetic activities, gut microbiota composition, the anti-inflammatory effects of Scutellaria-coptis herb couple against insulin resistance-model of diabetes involving the toll-like receptor 4 signaling pathway. J Ethnopharmacol. 2019;237:202-214. doi:10.1016/j.jep.2019.02.040

54. Cho Y, Challa S, Moquin D, et al. Phosphorylation-driven assembly of the RIP1-RIP3 complex regulates programmed necrosis and virus-induced inflammation. Cell. 2009;137(6):1112-1123. doi:10.10 16/j.cell.2009.05.037

55. Levine B, Mizushima N, Virgin HW. Autophagy in immunity and inflammation. Nature. 2011;469(7330):323-335. doi:10.1038/nature 09782

\section{Publish your work in this journal}

Drug Design, Development and Therapy is an international, peerreviewed open-access journal that spans the spectrum of drug design and development through to clinical applications. Clinical outcomes, patient safety, and programs for the development and effective, safe, and sustained use of medicines are a feature of the journal, which has also been accepted for indexing on PubMed Central. The manuscript management system is completely online and includes a very quick and fair peer-review system, which is all easy to use. Visit http://www. dovepress.com/testimonials.php to read real quotes from published authors. 